\title{
ONLINE OR OFFLINE SUPERVISION? POSTGRADUATE SUPERVISORS STATE THEIR POSITION AT UNIVERSITY OF SOUTH AFRICA
}

\author{
M. T. Gumbo \\ Department of Science and Technology Education \\ University of South Africa \\ Pretoria, South Africa \\ e-mail: gumbomt@unisa.ac.za
}

\section{ABSTRACT}

The demands of postgraduate supervision are huge for supervisors. These demands can however be lessened by taking advantage of the online operated information and communication technology (ICT). Supervising online provides important tools and/or applications which are the 21 st century era enablers of supervision especially in an open and distance learning (ODL) institution such as University of South Africa (UNISA). The supervisor-student working relationship, however, presents a human aspect that should take precedence over technology and thus guide how technology can be used in supervision. It is in this light that this reported study inquired into the supervisors' knowledge of the technological tools and their stance in the use of (online) technology in their supervision given the human aspect. UNISA's hundred-and-twentynine supervisors who are attached to College of Education (CEDU) were investigated in this study with respect to their supervision characteristics and exposure to technology and level of knowledge of the technological tools. That was followed up by face-to-face interviews with seven supervisors to determine their stance about the use of technology given the human aspect of students. The findings showed that the supervisors are knowledgeable in terms of the tools or applications such as MS Word, myUnisa and Discussion Forum. Furthermore, the findings indicated that there is a need for the training of other supervisors with respect to the use of certain online applications and/or tools. The most important finding is that supervisors value the human aspect such that though supervisors are positive about the role of technology in supervision, the human aspect should enjoy precedence in their supervision of students.

Keywords: supervisors, successful, knowledge, ICT/technological tools, postgraduate students.

\section{INTRODUCTION}

This study is and extension of the study by Gumbo (2018) which investigated the supervisors' knowledge and use of the technological tools for postgraduate supervision. Online tool based postgraduate supervision promises to alleviate the work of supervisors especially in an ODL environment in the era that is ruled by technology, online interaction and social networks. This study reports CEDU supervisors' views about the use of online tools or applications. These are 
supervisors of master's and doctoral students, acronymised as MEd DEd for reference to the field of education. As stated in the abstract, CEDU supervisors were target participants in the study. The use of online applications or tools for purposes of postgraduate supervision is an under researched area (McKavanagh, Bryant, Finger and Middleton 2004; Valetsianos 2010; Gumbo 2018). However, the extent to which supervisors use technology in their supervision work entirely depends on the views that they hold about its value and role. Hence, the research questions that were addressed are stated as follows:

- What are supervisors' supervision characteristics and success rate as assisted by technology?

- What are supervisors' knowledge level of (online) applications or tools for purposes of their supervision?

- What are these supervisors' stance regarding (online) applications or tools and their supervision service to the students?

A technological device such as smart cellphone harbours the tools and social media applications that are available for use for postgraduate supervision with a possible improvement in throughput in the ODL context. A computer and smartphone form part of ubiquitous ICT (Evans, Martin and Poatsy 2010) that can help achieve this (Wheeler 2010, 1). In fact, the 21st century educational practice is almost unthinkable without them the engagement of technology. It is transforming the working style, performance and production (Mbangwana 2008; Gumbo 2018). It is useful for carrying out research, e.g. in the visual representation of data such as through graphics tools and statistical and qualitative data analysis of data (McKavanagh et al. 2004). Knowledgeable supervisors in tools such as these can help their students.

My involvement in the management of the postgraduate programme in CEDU between 2010 and 2014 brought to my attention that the high number of postgraduate students partly added the supervision problems and affected throughput ultimately. Online technology presents one of the solutions that can be considered in the management of and carrying out supervision effectively. ODL students are mostly those who work, have family commitments. These students would rather prefer a "virtual" institution to a contact one (Stacey in Stacey and Fountain 2001, 519). This puts premium to the online technology in as far as managing the remoteness that characterises postgraduate supervision. For purposes of supervision then, ICT can improve productivity when it comes to the students' work, facilitate information management and communication for and between the students and supervisors, and transform 
students' research training into research. This can happen in instances such as the use of track changes tool when reading and commenting on their work, send email, on-time feedback, etc. (Abiddin, Ismail and Ismail 2011; Roets 2013).

My experiences in my involvement in the management of postgraduate programme as stated above are also coloured by the human aspect. I realised that it may not really be about technology, but more about the caring attitude from the side of the supervisors that matters most. If, for instance, a supervisor seems not to care at all about the student's personal circumstances, that would add to incompletion rate issues, sour working relationships, demotivation, and so forth, on the part of the student. I have had to mediate in some cases to restore the supervisor-supervisee working relationships. It is important to realise that a supervisor-student interaction is informed by a professional mutual engagement, respect, collegiality and open-mindedness, but also by converging and diverging interests (Abiddin et al. 2011). Supervisors approaching their supervision faced with such challenges tend to embrace transformation and are thus prepared to go an extra mile to resource their students and help them succeed. Students who do not have the luxury of exposure to technology may need extra attention in the face of technologically advanced environments requiring independent research. This is even more so in ODL, especially with regard to operating via the electronic media (Abiddin et al. 2011; Gumbo 2016) in which the operations are enmeshed in a vortex of technological change and speed, that is, open learning, flexible learning and minimal campus attendance courses (Evans 1995). This suggests that care should be taken to show an understanding of students and their contextual needs (Evans 1995, 23).

The next section discusses the theoretical frameworks for the study.

\section{THEORETICAL FRAMEWORKS}

I adopted technological pedagogical content knowledge (TPACK) as a guiding framework for the study. This framework suggests that technology is a vehicle for the delivery of content using the appropriate or even effective methods. The crux of the framework lies in the methods which directly implicate resources/equipment needed for teaching. Pedagogical knowledge therefore means possessing a deep knowledge of the methods of teaching and learning which are guided by educational purposes, values, aims, etc. (Harris, Mishra and Koehler 2009). In a research characterised postgraduate supervision, this would mean finding the technology driven methods to carry out and manage the supervision of one's students' work.

The works of Mishra and Koehler (2006) and Koehler and Mishra (2008; 2009) gave rise to the addition of technology in the mix of Shulman's (1987) pedagogical content knowledge (PCK) framework. TPACK motivated the introduction of a modified framework in educational 
research to build on the comprehension of teacher knowledge from the point of view of effective integration of technology (Mishra and Koehler 2006). TPACK then added to the conceptual developments of the 21 st century in this regard (Koehler and Mishra 2008). Thus, TPACK is a useful frame describing the goals of the use of technology in education.

The human element brings a different understanding in the game of supervision which contributes an important insight in this study. In light of this, too much emphasis on technology may compromise the attachment that the supervisor-supervisee working relationship can bring, which is naturally a desired expectation especially considering the face-to-face educational background that students have transited from. This suggests the blending of TPACK with community of practice (CoP) theory by Lave and Wenger (1991) to ensure the uncompromising of the human element. The scholars initiated the theory in their quest to explore apprenticeship through which they understood situated scholarship. The authors opine that learning (research in this study) is a communal event that divorces itself from the more conventional mental (Lave 1993). According to Barab, Barnett and Squire $(2002,495)$, a CoP is a group of people who are defined by co-dependence and choose to pursue communally defined ventures, activity or commitment, viewpoints and understandings in a time period. One could apply the understanding of this concept in a tertiary institutional, i.e. the academic CoP. From this understanding, students work collectively and share joint practices (Barab et al. 2002, 495) with their supervisors and fellow students. CoP can therefore be related to the philosophy of botho (in Setswana), which is commonly known as ubuntu in isi-Zulu. In my supervision practice I try to blend TPACK and CoP through "My M\&D Students" WhatsApp group in which they interact with one another and me as the supervisor, exchange ideas, post words of encouragement and sympathy when situations dictate so. For those who want to personally visit me about their work or communicate via skype, Scopia, etc, I do allow them to do so. I have noticed that seeing my face illuminates their attachment and engagements.

Academic engagements in African institutions should embrace the botho principles as many students that they serve hail from indigenous environments which are deeply enshrined in botho. It is in this light that botho means "an African value system that means humanness or being human, a worldview characterised by such values as caring, sharing, compassion, communalism, communocracy and related predispositions" (Khoza 2005 in Mabovula 2011, 42). Khoza (2005) (in Mabovula 2011) adds that the philosophy of botho can be applied universally even though botho has its roots in the African culture. Masango $(2006,931)$ adds a biblical dimension to the definition, and claims that man possesses a divine goodness which was God endowed, which transformed him into a human being, and thus facilitated humanness (botho). Botho is therefore the quality of being human. From a botho point of view, one's 
personhood fulfils another's personhood. One is, because the other one is. They, and as many other as can be, are a community. From a community another element of humanness surfaces, i.e. communalism. Communalism refers to a collective existence and inter-subjectivity based on support for one another, cooperation, collaboration and solidarity (Khoza 2005 cited in Mabovula 2011, 266).

From the above, it can be gathered that supervision requires a good mixture of the use of technology and the human side of those engaged in a CoP. Most importantly, students need caring supervisors who show interest in their personal circumstances and team up with them as a community that wants to achieve a set goal, i.e. completing a master's or doctoral research study. The application of a CoP, spiced with botho, will ensure motivation in the students even in the face of the demands of their studies. For instance, a caring supervisor will share important information such as a literature source with their student via e-mail or google drive, show compassion without compromising the standards, try to understand things from the side of the student, and so forth.

In the next section the research design and methods that were used in conducting this study are discussed.

\section{RESEARCH METHODOLOGY}

A mixed methods QUANT-Qual research design was followed in the study (McMillan and Schumacher 2014). Firstly, a questionnaire was designed which was used to gather information about the description of the supervisors' supervision characteristics and their perceptions about their knowledge of the technological tools (Creswell 2009, 388). The questionnaire also had items about the applications or tools the development of which was guided by the TPACK framework. The questionnaire contained a four-point Likert scale. It was divided into three sections which are explained as follows:

- Section A: This section targeted the supervisors' characteristics, e.g. seniority from lecturer to full professor, years of supervision (experience), number of supervised students, etc. The purpose of asking this information was to determine the success of supervision.

- Section B: In this section the supervisors were required to choose from the options that the scale provided, their knowledge level pertaining to the ICT tools. The options were described as 1) thorough knowledge 2) good knowledge 3) basic knowledge 4) no knowledge at all. In addition to this section, supervisors had to mention the tools not covered in the list, and their knowledge level of the tools. 
- $\quad$ Section C: This was the short section which asked open-ended? The questions had to do with whether the tools or applications played any role in the success of the supervisors' supervision.

Ethical clearance and permission to involve UNISA were granted. I subjected the questionnaire to a pre-test in order to ensure its content validity. Ten supervisors participated in the pre-test. These did not form part of the actual data collection. The pre-test led to minimal adjustments in the structural of the questionnaire.

All the 129 supervisors in CEDU were asked to fill in questionnaire. Homogeneity was their defining characteristics (Glasow 2005), i.e. they were experts in the field of education, thus responsible for teacher training. The target participants did not include external supervisors; they supervised through independent contracts and would thus not provide the required information.

The ICT Department and Department of Curriculum and Learning Development at UNISA provided data about the existing applications or tools as well as ICTs. Next, the supervisors were involved by providing information about their knowledge level regarding the applications or tools and ICTs. They also had to provide information about their use of the tools or applications and ICTs for supervision purposes specifically. I emailed the questionnaire, which contained the guidelines, to the supervisors to fill.

The survey was followed by face-to-face interviews with the supervisors to further gather supervisors' views about servicing their students via technology and thus their stance about the use of technology. The interview guide was therefore developed subsequent to the analysis of the data gathered through the questionnaire to follow up on certain areas. Seven supervisors were conveniently (time and availability) selected to participate in the interview in their respective offices. These supervisors were spread according to their seniority. An interview guide was designed based on the findings of the survey. All seven were interviewed and the newly added views surfaced with each interviewee. The interviews were recorded with the supervisors' consent and their transcription done after the completion of each, so memberchecking and follow-up could be done as a matter of immediacy whilst the data were still fresh in my mind.

The statistical analysis done by using IBM SPSS Statistics. Cronbach's alpha and exploratory factor analysis became instrumental in assessing the reliability and the validity of the questionnaire. In this case the internal consistency or average correlation of items in the instrument was determined to gauge its reliability. Furthermore, I used descriptive statistics which included the mean, standard deviation, proportions skewness and kurtosis to explain the 
patterns and trends in the data. Reliability means that a scale reflects the construct measured in a consistent manner (Field 2006; Hair et al. 2014). Then the instrument was checked for internal consistency to ensure that its items were unified (Salkind 2012). Reliability is determined by a high alpha value - they attest that items are measuring an underlying construct. In terms of this, the values range from 0.5 for unacceptable to 0.9 for excellent (George and Mallery 2003, 231) in which a value of 0.7 or more means that the scale is reliable (Hair et al. 2014, 123). Hence, 0.7 was also adopted as an acceptable level. The questionnaire that was used to collect data showed the Cronbach's Alpha of 0.935 for the construct "knowledge level" of tools (34 items), and 0.959 for the construct "issues concerning tools utilisation and supervision" (16 items). The rest of the other dimensions showed a Cronbach Alpha of more than 0.7. The whole questionnaire showed 0.938 reliability which falls within the excellent category. Hence, the overall questionnaire satisfactorily reliable.

Regarding the interviews, a commitment was made to read the data transcripts three times to familiarise myself with the data. Coding of the data followed which built up to their segmentation and pattern forming. Then two main themes were formed under which the findings were presented. Data were looked at across the quantitative and qualitative data and discussed ultimately.

\section{FINDINGS}

\section{Supervisors' supervision characteristics}

The study registered a response rate of 51 supervisors. These included the seniorities from lecturer to full professor. These supervisors, who were participants in the study, had to select the number of years of their supervision of MEd and DEd students from the options given in the questionnaire. They had to indicate as to whether they were trained towards supervision. They also had to indicate as to how many MEd and/or DEd students they had supervised successfully or unsuccessfully up to the time of investigation. The participating supervisors had 32 years supervision experience minimum. That gave a range of 31 years' experience presented in terms of the statistical summary with the values indicated in brackets thus: mean (8.775), media (6.000), mode $\left(1.000^{\mathrm{a}}\right)$, standard deviation (7.927), skewness (1.124), kurtosis (0.549), maximum (32.00), minimum (1.00), range (31.00), coefficient of variation (90.34\%). It can be gathered that mean experience stands at 8.77 and standard deviation at 7.93 (rounded off). This finding indicates an average of 9 years of the supervisors' supervision experience. A conclusion that can be drawn from this finding is that the supervisors were well experienced in postgraduate supervision. They were also familiar with matters of supervision. A median value of 6 years 
indicates that 50 per cent of the supervisors had at least 6 years of supervision experience. However, the finding also shows a high coefficient of variation $(90.34 \%)$ which indicates the varied spread of the supervisors' supervision experience.

Regarding the supervisors' exposure to training about the use of (online) tools or applications specifically for supervision purposes, approximately 25.5 per cent $(n=13)$ were train and 75.5 per cent $(n=38)$ were not trained. This translated into $1 / 4$ of supervisors who were trained about the use of (online) tools or applications.

There were 45 valid responses from the supervisors about the number of MEd students whom they had supervised successfully. It is important to state that the values of responses ranged from 0 to 45 . What this implies is that certain students had not succeeded in their dissertations; this could also mean that certain supervisors had yet to supervise a dissertation successfully. The statistical summary of this variable is indicated as follows: mean (6.70), median (4.00), mode $\left(0.00^{\mathrm{a}}\right)$, standard deviation (8.715), skewness (2.450), kurtosis (7.791), maximum (45.00), minimum (0.00), range (45.00), coefficient of variation (130.07\%). The average of supervisors who supervised MEd students successfully is 6.70 (7 students who completed their dissertations successfully). The standard deviation is indicated as 8.76 years, plus a coefficient of variation which indicates 130.07 per cent, showing a large variability in supervisors who registered the successful supervision of MEd students.

A total of 47 supervisors responded to this item about the number of DEd students whom they had supervised successfully. The statistical summary of this variable is indicated as follows: mean (2.83), median (0.00), mode $\left(0.00^{\mathrm{a}}\right)$, standard deviation (4.797), skewness (2.148), kurtosis (4.508), maximum (21.00), minimum (0.00), range (21.00), coefficient of variation $(169.51 \%)$. The responses indicated that the supervisors supervised DEd students successfully. However, the number of supervisors who did not supervise DEd students successfully stood at about 50 per cent $(51 \%$; $n=24)$, while that of supervisors who had not supervised DEd students to completion was 23 (48.9\%), giving a range of 21 . This finding shows an average of 2.83 DEd students, indicating that each supervisor had supervised about 3 students to completion. The finding also indicates a standard deviation of 4.797 and 169.51 per cent coefficient of variation, which shows further a large variability in supervisors who supervised DEd students successfully. The 0 median and modal values indicate the fact that a minimum of 50 per cent of the supervisors did not show any successes in DEd supervision.

The findings show that 45 supervisors had not supervised MEd students successfully. However, 30 (66.7\%) supervisors had 0 MEd students with regard to unsuccessful supervision with only 8 supervisors from this number who did not have any experience in supervising MEd students. the implied conclusion from this finding is that 53.3 per cent (24) of the supervisors 
did fail to supervise MEd students. The statistical summary of this variable is indicated as follows: mean (0.96), median (0), mode $\left(0^{\mathrm{a}}\right)$, standard deviation (1.731), skewness (2.188), kurtosis (4.955), maximum (7), minimum (0), range (7), coefficient of variation (180.31\%). The finding indicates that the average failure rate of MEd supervision is about one student per supervisor. An average of 0.96 evidences this indication. The findings show a standard deviation of 1.731 and 180.31 per cent coefficient of variation which indicates a large variability gathered from the furtherance of the coefficient of variation from zero, hence, there is no variability.

Then, for DEd unsuccessful supervision, there were 45 valid responses. The findings indicate that $37(82.2 \%)$ supervisors had 0 students, inferring that they did not supervise any student to completion or were not unsuccessful in supervising students who completed their theses. In specific terms, therefore, 24 of these supervisors had not supervised any students to completion. This indicates further that 28.9 per cent $(n=13)$ supervisors had 0 DEd students who completed their theses unsuccessfully. The finding tells us that these supervisors had a 100 per cent success rate in their supervision of DEd students. The statistical summary of this variable is indicated as follows: mean $(0.51)$, median $(0)$, mode $\left(0^{\mathrm{a}}\right)$, standard deviation (1.456), skewness (3.516), kurtosis (12.628), maximum (7.00), minimum (0), range (7.00), coefficient of variation $(285.49 \%)$. From this finding, the mean number of DEd students whom the supervisors supervised unsuccessfully is indicated as 0.51 . This indicates about one student per supervisor, and 1.456 standard deviation. The 285.49 per cent coefficient of variation is far from 0 , which indicates a large variability. The 0 median and modal values indicate that 50 per cent of the supervisors had 0 supervision success.

The computation of new variables was done in order to determine the supervisors' success rate in percentage form. There were 36 valid responses in the MEd as regards the supervision success rate. From the findings, 36 supervisors who submitted their students' dissertations had success or no success. The statistical summary of this variable is indicated as follows: mean (81.23), median (100), mode (100 $)$, standard deviation (29.8609), skewness (-1.783), kurtosis (2.525), maximum (100), minimum (0), range (100), coefficient of variation $(36.76 \%)$. The average success rate of MEd supervision as revealed from the findings is 81.23 per cent. The findings show 29.8609 standard deviation and 36.76 per cent coefficient of variation. It can be concluded that on average, 4 out of every 5 MEd students supervised completed their MEd dissertation successfully. There is minimal variability indicated by 36.76 per cent which is closer to 0.

Regarding the success rate of DEd supervision, 22 valid responses were realised, meaning that the supervisors only managed to supervise 22 DEd students to completion, and 14 (63.6\%) 
of these supervisors realised a 100 per cent success rate, resulting in only 4.5 per cent $(n=1)$ supervisors from this number who had a 0 per cent success rate. The statistical summary of this variable is indicated as follows: mean (82.90), median (100), mode $\left(100^{\mathrm{a}}\right)$, standard deviation (30.1083), skewness (-1.778), kurtosis (2.085), maximum (100.00), minimum (0), range (100.00), coefficient of variation (36.32\%). The findings show the mean success rate of 82.90 per cent for the supervision of DEd students, which indicates on average 4 out of every 5 who were supervised by each supervisor had successfully completed their theses. The 100 per cent median and modal values and 36.32 per cent coefficient of variation, which lies closer to 0 is an indication of minimal variability. This can be further explained by the ratio of the standard deviation to the mean, which is $36: 1$.

\section{Supervisors' knowledge level of tools or applications}

In this instance the supervisors rated their knowledge level about the applications or tools guided by the 4-point scale explained in the methodology section above. Their knowledge level was measured by combining the "good knowledge" and "thorough knowledge" categories. Table 1 shows their knowledge level in this regard.

Table 1: Supervisors' knowledge level about applications or tools

\begin{tabular}{|c|c|c|c|c|c|}
\hline \multirow{2}{*}{ Applications/tools } & \multicolumn{4}{|c|}{ Level of knowledge } & \multirow[t]{2}{*}{ Rank } \\
\hline & TK & GK & BK & NKAA & \\
\hline SMS & $68.0 \%(34)$ & $22.0 \%(11)$ & $6.0 \%(3)$ & $4.0 \%(2)$ & 1 \\
\hline E-mail (Outlook) & $64.0 \%(32)$ & $26.0 \%(13)$ & $6.0 \%(3)$ & $4.0 \%(2)$ & 1 \\
\hline MS Word & $56.9 \%(29)$ & $31.4 \%(16)$ & $7.8 \%(4)$ & $3.9 \%(2)$ & 3 \\
\hline Computer & $45.1 \%(23)$ & $43.1 \%(22)$ & $11.8 \%(6)$ & - & 3 \\
\hline Laptop & $43.1 \%(22)$ & $45.1 \%(23)$ & $9.8 \%(5)$ & $2.0 \%(1)$ & 3 \\
\hline PowerPoint & $49.0 \%(24)$ & $32.7 \%(16)$ & $12.2 \%(6)$ & $6.1 \%(3)$ & 6 \\
\hline myUnisa & $35.3 \%(18)$ & $45.1 \%(23)$ & $15.7 \%(8)$ & $3.9 \%(2)$ & 7 \\
\hline WhatsApp & $44.9 \%(22)$ & $30.6 \%(15)$ & $16.3 \%(8)$ & $8.2 \%(4)$ & 8 \\
\hline Data projector & $37.3 \%(19)$ & $33.3 \%(17)$ & $19.6 \%(10)$ & $9.8 \%(5)$ & 9 \\
\hline Bulk SMSs & $37.5 \%(18)$ & $27.1 \%(13)$ & $20.8 \%(10)$ & $14.6 \%(7)$ & 10 \\
\hline Discussion forum & $42.0 \%(21)$ & $22.0 \%(11)$ & $16.0 \%(8)$ & $20.0 \%(10)$ & 11 \\
\hline Search engines & $26.0 \%(13)$ & $38.0 \%(19)$ & $22.0 \%(11)$ & $14.0 \%(7)$ & 11 \\
\hline Whiteboard & $30.6 \%(15)$ & $28.6 \%(14)$ & $12.2 \%(6)$ & $28.6 \%(14)$ & 13 \\
\hline Video conferencing & $15.7 \%(8)$ & $27.5 \%(14)$ & $27.5 \%(14)$ & $29.4 \%(15)$ & 14 \\
\hline Skype & $17.0 \%(8)$ & $25.5 \%(12)$ & $29.8 \%(14)$ & $27.7 \%(13)$ & 15 \\
\hline Facebook & $16.3 \%(8)$ & $22.4 \%(11)$ & $32.7 \%(16)$ & $28.6 \%(14)$ & 16 \\
\hline BBM & $27.3 \%(12)$ & $11.4 \%(5)$ & $20.5 \%(9)$ & $40.9 \%(18)$ & 17 \\
\hline Excel & $16.0 \%(8)$ & $20.0 \%(10)$ & $40.0 \%(20)$ & $24.0 \%(12)$ & 18 \\
\hline Dropbox & $17.4 \%(8)$ & $17.4 \%(8)$ & $30.4 \%(14)$ & $34.8 \%(16)$ & 19 \\
\hline Google Drive & $24.5 \%(12)$ & $8.2 \%(4)$ & $34.7 \%(17)$ & $32.7 \%(16)$ & 20 \\
\hline Blog & $8.5 \%(4)$ & $23.4 \%(11)$ & $23.4 \%(11)$ & $44.7 \%(21)$ & 21 \\
\hline Twitter & $8.3 \%(4)$ & $18.8 \%(9)$ & $25.0 \%(12)$ & $47.9 \%(23)$ & 22 \\
\hline
\end{tabular}




\begin{tabular}{|l|r|r|r|r|c|}
\hline \multirow{2}{*}{ Applications/tools } & \multicolumn{4}{|c|}{ Level of knowledge } & \multicolumn{1}{c|}{ Rank } \\
\cline { 2 - 6 } & TK & \multicolumn{1}{c|}{ GK } & \multicolumn{1}{c|}{ BK } & \multicolumn{1}{c|}{ NKAA } & 23 \\
\hline SignUp & $12.8 \%(6)$ & $10.6 \%(5)$ & $27.7 \%(13)$ & $48.9 \%(23)$ & 24 \\
\hline E-reader & $8.5 \%(4)$ & $14.9 \%(7)$ & $27.7 \%(13)$ & $48.9 \%(23)$ & 25 \\
\hline Podcast & $6.1 \%(3)$ & $16.3 \%(8)$ & $30.6 \%(15)$ & $46.9 \%(23)$ & 26 \\
\hline WeChat & $8.7 \%(4)$ & $13.0 \%(6)$ & $23.9 \%(11)$ & $54.3 \%(25)$ & 27 \\
\hline Wikis & $10.6 \%(5)$ & $10.6 \%(5)$ & $14.9 \%(7)$ & $63.8 \%(30)$ & 28 \\
\hline ooVoo & $12.8 \%(6)$ & $4.3 \%(2)$ & $6.4 \%(3)$ & $76.6 \%(36)$ & 29 \\
\hline RSS & $6.7 \%(3)$ & $8.9 \%(4)$ & $13.3 \%(6)$ & $71.1 \%(3)$ & 30 \\
\hline Mendeley & $6.3 \%(3)$ & $6.3 \%(3)$ & $12.5 \%(6)$ & $75.0 \%(36)$ & 31 \\
\hline Social bookmaking & $2.1 \%(1)$ & $8.5 \%(4)$ & $12.8 \%(6)$ & $76.6 \%(36)$ & 32 \\
\hline Screen & $2.2 \%(1)$ & $4.4 \%(2)$ & $11.1 \%(5)$ & $82.2 \%(37)$ & 33 \\
\hline Syndication & $2.1 \%(1)$ & $2.1 \%(1)$ & $12.8 \%(6)$ & $83.0 \%(39)$ & 33 \\
\hline $\begin{array}{l}\text { Tag-based } \\
\text { folksonomies }\end{array}$ & $2.1 \%(1)$ & $2.1 \%(1)$ & $10.6 \%(5)$ & $85.1 \%(40)$ & 2 \\
\hline
\end{tabular}

TK: thorough knowledge, GK: good knowledge, BK: basic knowledge, NKAA: no knowledge at all

Table 1 shows the applications or tools in which the supervisors' knowledge level was above 70 per cent. These include SMS, E-mail (Outlook), MS Word, Computer, Laptop, PowerPoint, myUnisa, WhatsApp and Data projector. It should be noted that the list of tools or applications even included devices themselves, e.g. the laptop. This helped to give an idea about the source or application platform of the tools. Table 1 also shows the tools or applications about which more than 70 per cent of the supervisors had no knowledge about. These include Tag-based folksonomies, Syndication, Screen, ooVoo, Social bookmaking, Mendeley, RSS. Furthermore, the supervisors had to mention the tools or applications not covered in the questionnaire that they had knowledge about. Viber, Google Scholar, LinkedIn, Turnitin, Kik, EViews tools and Facetime are among the many that the supervisors added and which they had thorough knowledge about but not for supervision purposes necessarily.

\section{Role that the applications or tools can play in supervision success}

The findings reveal that supervisors were positive about the applications or tools contributing towards the successful supervision of their students. Few supervisors avoided responding to the question and few others were undecided. The supervisors appreciated ICTs and online tools for the role they play in improving the supervisor-student communication and broadening the student intellectually as well as improving better access to sources. They further alluded to the fastness of technology in providing feedback to students. One supervisor stated thus, "using track changes in MS Word helps with providing guidance on argumentation, formulation, logic". This supervisor also stated that he helped students to locate sources by savving the internet and pointing them to the URLs, sent them articles and websites through e-mail when necessary. Another supervisor commented that her knowledge of "using a computer and 
working online had helped her supervision successfully and effectively".

\section{Interviews}

Findings from the interviews highlighted the two important issues in relation to the research questions: the value and role that technology plays in their supervision of the students' work, and the human aspect, that needs to be considered seriously, which may not be technology dependent per se. These themes guided the presentation of findings.

\section{Value and role of technology in supervision}

The supervisors acknowledged the fact that we live in a digital age, and that they therefore needed to integrate technology in their supervision. Between e-mail, videoconferencing, Discussion Forum, telephone, WhatsApp, Facetime, Viber, Mendely, Track Changes, myUnisa, Turnitin, ATLAS.ti, SPSS and Skype, supervisors predominantly used ubiquitous technological tools, that is, e-mail, telephone, myUnisa and Discussion Forum. Generally, the supervisors alluded to the value and importance of the technological tools in their supervision. "I did not receive any training. I was thrown in the deep end" [Supervisor 1]. However, this supervisor valued technology in relation to the ODLness of supervision, as he explained: "Yaa, I think it's unthinkable, especially if you work at Unisa because students are not here on campus. It cannot work at all without technology". Supervisor 2 gave the transformative perspective of word processing: "What would we be without the word processing? For many years we worked on hard copies, and you had to do it in pencil". According to Supervisor 2, "students can save at least a year, if not two. If you would look at the number of students that I have supervised in the last five years, since technology became part of our lives versus the previous years, I can assure you that my output per year probably doubled or was $50 \%$ more." In a similar sense, Supervisor 3 corroborated that "technological tools make it easier", and indicated that without the use of technological means, "the student will take long" as they will have to go to the library to ask for books, journals, periodicals, and all those things. With technological means "we are able to work faster" [Supervisor 4], and "it helps a student who uses ICT to finish quicker" [Supervisor 5]. The supervisors appreciated the fact that technology and working online provided the platform for them to identify the e-resources useful for their student's work. Supervisor 7 referred to technology as being "fantastic".

To attest to the delay that the non-use of technology may cause, Supervisor 4 related the trouble it took two of her students who "drove all the way from Mpumalanga to bring their hard copies". This in turn delays their feedback, as opposed to students who "submit their work by e-mail; within a week they will get my response" [Supervisor 2]. But there were also challenges 
with students not being able to use the tools properly, for example, "they will only accept the track changes that I am making without engaging with them" [Supervisor 6]. This situation is exacerbated by the students who struggle to afford a computer - "two students who do not have computers. My one student is there from the Cape, very poor, disadvantaged environment" [Supervisor 7]. Some may have a computer but cannot operate it, like in the case of Supervisor 4's students who travelled from Mpumalanga; they said, "Yaa! Endlini ikhona ilaptop" (in isiZulu), meaning "Yes, we have a laptop in the house".

The contextual demands pertaining to the third world, culture and language made two supervisors build a dimension that bridged into the next theme. They emphasised the human aspect, as Supervisor 7 related: "So, even if you use technology, technology is instrumental to help and support students to become academic scholars. So, technology is not about technology, it's about a human being, a student with academic dreams". According to this supervisor, technology can be used to bridge the distance in ODL, but distance can still be there depending on the treatment of students: "It is a distance, there is a distance, and remembered her student commenting: "You have used everything, but I can't hear you", and referred to it as students' "authentic voice of understanding", as she brought in the student's voice again: "I am struggling. But where is your voice of understanding how difficult it is?" This supervisor discouraged "over-emphasising the use of technology, but using technology and integrating it as part of your teaching approach. In an ODL context, specifically at Unisa, we so much emphasise student support”. So, it is not all about technology, as Supervisor 4 added, that "students still believe in a word of mouth, face-to-face conversation. So, I think there is spoken language and also you cannot replace the teacher with technology."

\section{The human aspect: Looking beyond technology in supervision}

The supervisors' views emphasised the working relations aspect in the supervision. Their views created an understanding of not losing sight of the humanness of the students by allowing oneself to be carried away by technology. This even affected how the supervisors used the technological tools. Supervisor 2 did not prefer using the MS Word Track Changes tool as that frustrated students. She compromised for the comments function, "but I make corrections on the electronic copy". As part of feedback to the students, she included a letter of comments. In addition, she valued oral feedback "because sometimes there is a misunderstanding; you mean something and the student understands something different, but you can clarify that when you talk. I once had a student whom I referred to a table, meaning table 3.5, and the student was thinking of actual table with chairs, and I mean there was such confusion."

Supervisor 7 advanced a perspective that puts more weight on the personhood of students 
rather than technology, by involving the term lifeline. Her emphasis was on elevating the person more than the machine. She mentioned this lifeline about six times in the interview. Her responses were thus skewed towards the personal circumstances of her students and how she attempted to intervene. She explained: "and the student will write and say, 'My mother passed away' or 'My sister has problems'. So, that is a discussion forum, face-to-face. However, I also use discussion forums on my computer." For this supervisor, Discussion Forum was an interface between the students' humanness and technology (computer) - it meant Discussion Forum on myUnisa platform and discussion forum among her students, with the more experienced ones mentoring the inexperienced ones or strugglers. She indicated that students wanted to talk to her at times by seeing her face as she referred to her student who stated: "If I talk to you, I would like to see you, on a human side", to an extent the student asked: "I want a picture of you".

Supervisor 7 went on to emphasise emotional support as part of supervision when she related her other student's situation, quoting the student's words: "My son passed away and he was in matric. It is the end of the world now". The student was able to pick up the pieces after the support she received from her supervisor through words of encouragement: "I think that I will start with my doctoral degree". This student's courage was rejuvenated and she produced quality work to a point "she received first prize after Research and Innovation Day for doctoral students" [Supervisor 7]. Supervisor 7 used phrases that suggest investing in the success of students with the support due to them: "all need emotional support, patience for postgraduate students; holistic approach; work together as a team; complimentarily, collaboratively". This supervisor was also in a death situation and stated that as the student in a death situation asked, “"Will you pray for me', they will pray with me", referring to a reciprocal support between her and her students.

\section{DISCUSSION OF THE FINDINGS}

The findings reveal that the supervisors are reasonably experienced in matters of supervision and thus had excellent or good knowledge. The number of supervisors who had not yet risen to that level of experience and knowledge is rather low by comparative terms. Whatever the case, them working at an ODL university suggest that they be abreast with the advancement of and available technological applications or tools and the complexities of ICTs. However, the findings reveal that a small number $(1 / 4)$ of the supervisors had received training about supervision via the tools or applications. It thus appears that supervisors have still to be trained on gaining knowledge and skills about the available technology so that they can take full advantage thereof for purposes of their supervision. It also appears, however, that those who 
seem to be conversant with the tools applications had self-taught.

The narratives that resulted from the interviews illuminate this finding by emphasising the human aspect pertaining to the students, described as a lifeline. This angle of supervision helps to explain why some supervisors may not want to elevate technology above the human aspect, thus operating within a $\mathrm{CoP}$ or botho. Supervisor 4 and Supervisor 7 put more weight on this aspect, which supports the views of the consulted scholars in the likes of Masango (2006), Mabovula (2006) and Abiddin et al. (2011) that put more emphasis on the human side of things.

Quite several supervisors had supervised MEd students but that was counteracted by the unsuccessful students - they did not pass their dissertations. Yet several supervisors also had not supervised a dissertation to completion. A variety of supervision experience and knowledge was however noticed through two supervisors who had successfully supervised 29 and $45 \mathrm{MEd}$ students respectively. These are among those who were favoured by their years of experience and supervision knowledge, which made them have urge over many others. About halve of the supervisors had not been able to supervise DEd students to completion. The findings show an average of three students that individual supervisors had been able to supervise successfully. One cannot undermine the demands that a doctoral study puts on both the supervisor and student as stakes are high especially with regard to the student expected to rise to the complexity of the study, e.g. contribution, required sophistication in the treatment of research methods. There are yet the supervisors who had not supervised MEd or DEd students or even had not supervised successfully. The supervision success rate in both MEd and DEd is above 80 per cent. The most senior supervisors, namely, professors, have recorded the highest success rate, obviously because they have grown in their supervision experience. However, when corroborated with the qualitative data, these supervisors happen to be those who also value the respect, care, support, and so forth, due to their students, not technology only. The case of Supervisor 4 showing an understanding in the couple that hand-delivered their work, and Supervisor 7 showing emotional support to a student who was in a death situation, extended an idea of CoP or botho. In the case of Supervisor 7, the student could pick up the pieces and excelled ultimately. This is a sign that for supervision to be successful the human side of students should not be undermined.

Mbangwana (2008) has been cited as placing premium on applications or tools and ICTs as they can transform the supervision of students and make the supervisors achieve success. Therefore, supervisors could capitalise on TPACK by making effort to harvest from what it has to offer them (Mishra and Koehler 2006). But it seems that experience level and the other factors that were cited in the introduction carry much weight compared to the applications or tools and ICTs. Technology may do a good job (Stacey in Stacey and Fountain 2001; Mbangwana 2008), 
but this study's findings suggest that getting in touch with the human side of students should take precedence.

It is clear from the findings that the supervisors possessed knowledge of the common applications or tools and ICTs especially the ones that they had added to the list. Their knowledge of the applications or tools and ICTs is an indication that these are crucial for the success of supervision. The irony, however, is that at the time of this study only $1 / 4$ of the supervisors had been trained in the use of the applications or tools. This does not augur well considering the demands of the ODL university environment for academics to be conversant with the use of technology. The supervisors are however not opposed to the important role that technology can play in the facilitation of supervision, but they wouldn't downplay the bearing of the human aspect in supervision. The fact that some of them still are open to the students making appointments to visit them in their offices though the ideal of ODL might deny the students a face-to-face engagement, attests to the value that the supervisors place on the working relationship from the botho perspective. This finding contributes a noteworthy consideration in the attempt to involve technology to bridge the distance between the supervisor and student - the human aspect still takes precedence in some supervisors. Face-to-face interaction seems unwelcomed in the $21^{\text {st }}$ era where technology for teaching and learning is overemphasised. But the findings of this study suggest that supervising students in African contexts such as at UNISA still dictate that this mode of educational interaction may not be dismissed wholly. In the words of Supervisor 7: "So, even if you use technology, technology is not about technology, it's about a human being, a student with academic dreams". Thus, seeing the supervisor in a face-to-face engagement may make a difference by adding understanding, encouragement, bridging the distance in addition to technology, etc in the supervision.

To conclude the discussion, the term lifeline could explain the supervision interface of technology and the human aspect which yielded the supervision interface framework (SIF) motivated by lifeline concept. This framework is depicted in Figure 1.

\begin{tabular}{|c|c|c|}
\hline $\begin{array}{c}\text { Human aspect } \\
\text { (offline/human touch): } \\
\text { CoP/botho - care, respect, } \\
\text { community, support, etc. "I }\end{array}$ & $\begin{array}{c}\text { Lifeline } \\
\text { Blending zone } \\
\text { (technology }\end{array}$ & $\begin{array}{c}\text { Technology (online } \\
\text { tools/ICTs) }\end{array}$ \\
want to see you" & $\begin{array}{c}\text { TPACK: online, ICTs, e-mail, } \\
\text { and face-to- } \\
\text { face }\end{array}$ & technology may combine text \\
& and visualization \\
& engagements) & \\
\hline
\end{tabular}

Figure 1: Supervision Interface Framework 


\section{CONCLUSION AND RECOMMENDATIONS}

The aim that was pursued in this study yielded answers to the questions stated in the introduction. Hence, the research questions were answered. Firstly, the study yielded the characteristics of the supervisors which helped with the understanding of the success of their supervision. Secondly, the study explained the supervisors' knowledge level the available tools or applications for supervision - they were knowledgeable to a greater extent. According to the supervisors, supervising with the help of technology can alleviate the challenges of supervision and make them realise successful supervision. Thirdly and importantly, the study explained the supervisors' position about how far they think they can use technology in their supervision work vis-à-vis the human aspect. The main contribution of the study is the SIF that is anchored on the idea of the lifeline which crystallises the human aspect in the supervision work. Priority in the supervision relationship should not be accorded to the use of technology to the detriment of the student as a human being. The interface illustrated above should guide this working relationship. By implication, supervising from a botho perspective can make the supervisors to supervise within the SIF and thus carefully decide on the use of technology.

This study is limited with respect to the lack of a direct link between the use of the applications or tools and ICTs to the specific supervisors.

In light of the findings, it is recommended that:

- $\quad$ supervisors value the working relationships with their students in their supervision work so to respect the human aspect instead of being carried away by technology without discarding the latter necessarily - the SIF provides guidance in this respect;

- $\quad$ supervisors exposed to the wealth of applications or tools and ICTs that they can use to supervise their students successfully and effectively;

- $\quad$ in addition to their exposure, supervisors be trained to acquire more knowledge and skills about the use of technology for purposes of easy supervision;

- experienced supervisors should be encouraged to mentor inexperienced supervisors or supervisors who have not supervised especially a single MEd;

- more research be conducted about the value attached to the human aspect in supervision in the $21^{\text {st }}$ era in which there is too much emphasis on the use of technology in education. 


\section{REFERENCES}

Abiddin, N. Z., A. Ismail and A. Ismail. 2011. Effective supervisory approach in enhancing postgraduate research studies. International Journal of Humanities and Social Science 1(2): 206-217.

Barab, S. A., M. Barnett and K. Squire. 2002. Developing an empirical account of a community of practice: Characterising the essential tensions. The Journal of the Learning Sciences 11(4): 489542.

Creswell, J. W. 2009. Research design: Qualitative, quantitative and mixed methods approaches. Third edition. Los Angeles: Sage.

Evans, T. 1995. Postgraduate research supervision in the emerging "open" universities. Australian Universities' Review 2: 23-27.

Evans, A., K. Martin and M. A. Poatsy. 2010. Technology in action: Complete. $6^{\text {th }}$ Edition. New Jersey: Printice Hall.

Field, A. P. 2006. The behavioural inhibition system and the verbal information pathway to children's fears. Journal of Abnormal Psychology 115(4): 742-752.

Glasow, P. A. 2005. Fundamentals of survey research methodology. McLean: MITRE.

George, D. and P. Mallery. 2003. SPSS for Windows step by step: A simple guide and reference 11.0 update. Fourth edition. Boston: Allyn \& Bacon.

Gumbo, M. T. 2018. Online learning experiences of students in the MEd in Open and Distance Learning - A phenomenography of the dual university initiative. Unpublished MEd dissertation. Pretoria: University of South Africa.

Gumbo, M. T. 2018. University of South Africa supervisors' knowledge of technological tools and ICTs for postgraduate supervision. The Turkish Online Journal of Educational Technology 17(4): 5468.

Hair, J. F., G. T. M. Hult, C. M. Ringle and M. Sarstedt. 2014. A primer on partial least squares structural equation modelling (PLS-SEM). Thousand Oaks: Sage.

Harris, J. B., P. Mishra and M. Koehler. 2009. Teachers' technological pedagogical content knowledge; Curriculum-based technology integration reframed. Journal of Research on Technology in Education 41(4): 393-416.

Khoza, R. J. 2005. Let Africa lead. Sunninghill: Vezubuntu.

Koehler, M. J. and P. Mishra. 2008. Introducing TPACK. In AACTE Committee on Innovation and Technology (Ed.). Handbook of technological pedagogical content knowledge (TPACK) for educators. New York: Routledge.

Koehler, M. J. and P. Mishra. 2009. What is technological pedagogical content knowledge? Contemporary issues in technology and teacher education. http://www.citejournal.org/ vol9/iss 1/general/article1.cfm (Accessed 20 April 2017).

Lave, J. 1993. Introduction. In Understanding practice: Perspectives on activity and context, ed. J. Lave and S. Chaiklin. New York: Cambridge University Press.

Lave, J. and E. Wenger. 1991. Situated learning: Legitimate peripheral participation. Cambridge: Cambridge University Press.

Mabovula, N. N. 2011. The erosion of African communal values: A reappraisal of the African ubuntu philosophy. Inkanyiso, Journal of Humuman \& Social Sciences 3(1): 38-47.

Masango, M. S. S. 2006. African spirituality that shapes the concept of Ubuntu. Verbum et Ecclesia 27(3): 930-943.

Mbangwana, M. A. 2008. Introduction of ICT in schools and classrooms in Cameroon. http://www.rocare.org/changingMindsets/pdf/ch09-I (Accessed on 25 May 2017).

McKavanagh, C., K. Bryant, G. Finger and H. Middleton. 2004. Information and communication technologies and higher degree research supervision. Paper presented at the Annual International HERDSA Conference. Miri, Sarawak, Malaysia. 
McMillan, J. and S. Schumacher. 2014. Research in education: Evidenced-based inquiry. Seventh edition. Harlow: Pearson.

Mishra, P. and M. J. Koehler. 2006. Technological pedagogical content knowledge: A framework for integrating technology in teachers' knowledge. Teachers College Record 108(6): 1017-1054.

Roets, L. 2013. Learning through reflection: Supervising DRC master's degree students within the open distance and learning context. Journal of Nursing Education and Practice 3(10): 139-149.

Salkind, N. J. 2012. Exploring research. Eighth edition. New York: Pearson.

Shulman, L. S. 1987. Knowledge and teaching: Foundations of the new reform. Harvard Educational Review 57(1): 1-21.

Stacey, E. and W. Fountain. 2001. Student and supervisor perspectives in a computer-mediated research relationship. Paper presented at the 18th Annual Conference of the Australian Society for Computers in Learning in Tertiary Education (ASCILITE). Melbourne, Australia.

Valetsianos, G. (Ed.). 2010. Emerging technologies in distance education. AU Press: Athabasca University.

Wheeler, S. 2010. What is so innovative about ICT? http://steve-wheeler.blogspot.com/2010/04/whatsso-innovative-about-ict.html (Accessed on 27 June 2017). 